\title{
Efficacité et innocuité du plasma de convalescent en cas de forme grave de COVID-19, extrapolée de données relatives à d'autres formes graves d'infections respiratoires virales : revue systématique et méta-analyse
}

\author{
Niveditha Devasenapathy MBBS MSc, Zhikang Ye MPharm, Mark Loeb MD MSc, Fang Fang MD, \\ Borna Tadayon Najafabadi MD MPH, Yingqi Xiao MN, Rachel Couban MA MISt, Philippe Bégin MD PhD, \\ Gordon Guyatt MD MSc
}

Citation : CMAJ 2020 July 6;192:E745-55. doi : 10.1503/cmaj.200642-f; diffusion hâtive le 22 mai 2020

Voir la version anglaise de l'article ici : www.cmaj.ca/lookup/doi/10.1503/cmaj.200794; voir un article connexe (en anglais) ici : www.cmaj.ca/lookup/doi/10.1503/cmaj.200648

\section{RÉSUMÉ}

CONTEXTE : On ne connaît pas encore avec certitude l'innocuité et l'efficacité du plasma de convalescent comme traitement de la forme grave de la maladie à coronavirus 2019 (COVID-2019). Afin d'appuyer la conception de lignes directrices sur la prise en charge de la COVID-19, nous avons effectué une revue systématique et une méta-analyse sur l'utilisation du plasma de convalescent pour le traitement de cette maladie et d'autres formes graves d'infections respiratoires virales.

MÉTHODES : En mars 2020, nous avons effectué des recherches dans des bases de données biomédicales internationales et chinoises, des registres d'essais cliniques et des sources prépubliées afin de recenser des essais randomisés et contrôlés (ERC) et des études non randomisées comparant les issues de patients ayant reçu du plasma de convalescent à celles de patients n'en ayant pas reçu. Ont été inclus les patients ayant une infection aiguë attribuable à un corona- virus, au virus de l'influenza ou au virus Ebola. Nous avons également réalisé une méta-analyse à l'aide d'un modèle à effets aléatoires et évalué la qualité des données probantes au moyen de l'approche GRADE (Grading of Recommendations Assessment, Development, and Evaluation).

RÉSULTATS : Sur les 1099 études uniques initialement repérées, 6 étaient admissibles, et aucune d'entre elles ne portait sur des patients atteints de la COVID-19. Une étude non randomisée ( $n=40)$ sur l'administration de plasma de convalescent à des patients atteints du coronavirus du syndrome respiratoire aigu sévère (SRAS-CoV) a fourni des données peu concluantes sur le taux de mortalité (risque relatif [RR] 0,10 ; intervalle de confiance [IC] de $95 \%$ 0,01 à 1,70). Des estimations regroupées provenant de 4 ERC sur l'influenza ( $n=$ 572) n'ont pas montré d'effet manifeste sur le taux de mortalité (4 ERC; RR 0,94;
IC de $95 \%$ 0,49 à 1,81), le rétablissement complet (2 ERC; rapports de cotes [RC] 1,04 ; IC de $95 \%$ 0,69 à 1,64) et la durée d'hospitalisation (3 ERC; différence moyenne [DM] -1,62; IC de $95 \%-3,82$ à 0,58 jours). La qualité des données était très faible pour tous les paramètres relatifs à l'efficacité. Dans les ERC sur l'influenza, aucun ou peu d'événements indésirables graves ont été associés au plasma de convalescent (RR 0,85; IC de $95 \% 0,56$ à 1,29 ; données de faible qualité).

INTERPRÉTATION : Les études portant sur des formes graves d'infections respiratoires virales autres que la COVID-19 ont fourni des données indirectes de très faible qualité semblant indiquer que le plasma de convalescent n'offre aucun bénéfice ou offre des bénéfices minimes pour le traitement de la COVID19, de même que des données de faible qualité montrant qu'il n'entraîne pas d'événements indésirables graves. rès de 3 millions de personnes sur la planète ont reçu un diagnostic de maladie à coronavirus 2019 (COVID-19), et environ 0,2 million d'entre elles en sont décédées ${ }^{1}$. De nombreux patients atteints de la COVID-19 développent des troubles respiratoires aigus sévères nécessitant une hospitalisa- tion aux soins intensifs et, souvent, une ventilation mécanique ${ }^{2}$. Le taux de létalité de la COVID-19 pourrait être de 2,3\% chez l'ensemble des personnes ayant contracté le virus, et de $10 \%$ à $40 \%$ chez les personnes gravement malades ${ }^{3,4}$. Il faut de toute urgence trouver des traitements efficaces. 
Des données épidémiologiques et cliniques émergentes montrent à la fois des ressemblances et des dissemblances entre la forme grave de COVID-19, le syndrome respiratoire aigu sévère (SRAS) et le syndrome respiratoire du Moyen-Orient $(\mathrm{SRMO})^{5}$. Il est également possible que des traitements contre les formes graves d'infections par le virus de l'influenza testés durant la pandémie de grippe $\mathrm{H} 1 \mathrm{~N} 1$ et les éclosions de grippes $\mathrm{H} 5 \mathrm{~N} 1$ et $\mathrm{H} 7 \mathrm{~N} 9$ puissent guider les soins prodigués aux patients atteints d'une forme grave de COVID- $19^{6}$.

Parmi les divers traitements proposés pour lutter contre la COVID-197 , on compte l'administration de plasma de convalescent, qui est appuyée par des données montrant une diminution du taux de mortalité dans des cas d'infection par le virus Ebola ${ }^{8}$. Cette intervention a également été testée dans le cadre d'études sur d'autres infections respiratoires virales aiguës sévères ${ }^{6,9,10}$. Le plasma de convalescent est du plasma prélevé chez des personnes s'étant récemment remises d'une infection virale, dans lequel on s'attend à trouver un taux élevé d'anticorps polyclonaux dirigés contre le virus en cause ${ }^{11}$. Le plasma hyperimmun est quant à lui du plasma prélevé chez des personnes ayant des titres élevés d'anticorps neutralisants, sans égard au temps écoulé depuis l'infection virale. Des auteurs ont utilisé les 2 termes de façon interchangeable; comme la neutralisation virale n'est qu'un des mécanismes proposés pour expliquer l'effet antiviral des anticorps, on ne sait pas à quel point il est important de faire la distinction entre ces 2 types de produits (figure 1 ).

De façon générale, des cliniciens ont administré du plasma de convalescent à des patients aux prises avec une infection virale et dont l'état se dégradait malgré la prestation de soins de soutien ${ }^{6}$. Bien que l'on considère que la réduction de la virémie (immunité passive) soit le principal mécanisme d'action du plasma de convalescent ${ }^{12}$, on croit également qu'il stimule la réponse immunitaire (immunité active) chez le receveur ${ }^{13}$. La figure 1 présente les mécanismes par lesquels le plasma de convalescent pourrait contrer le coronavirus du syndrome respiratoire aigu sévère 2 (SRAS-CoV-2).

La synthèse systématique des données probantes disponibles sur l'efficacité et l'innocuité du plasma de convalescent pourrait orienter l'utilisation de ce produit chez les patients atteints de la COVID-19. Nous avons effectué une revue systématique des données sur le sujet pour appuyer des lignes directrices sur la prise en charge de la COVID-19 ${ }^{14}$. Comme nous nous attendions à ce que les données directes sur l'administration de plasma de convalescent en cas de COVID-19 soient rares, nous avons préparé une synthèse des données sur son administration dans le traitement du SRAS, du SRMO et de l'influenza, notamment les virus $\mathrm{H} 1 \mathrm{~N} 1, \mathrm{H} 7 \mathrm{~N} 9$ et $\mathrm{H} 5 \mathrm{~N} 1$, et nous nous sommes intéressés aux événements indésirables qui sont survenus chez les patients infectés par le virus Ebola.

\section{Méthodes}

Cette revue systématique et méta-analyse suit les lignes directrices PRISMA (Preferred Reporting Items for Systematic Reviews and Meta-Analyses) ${ }^{15}$ pour la production de rapports. Un docu- ment connexe présente le protocole de revue systématique suivi (annexe 1, accessible en anglais au www.cmaj.ca/lookup/ suppl/doi:10.1503/cmaj.200642/-/DC1).

\section{Sélection des études}

Nous avons retenu les études portant sur des patients infectés par le SRAS-CoV-2, le SRAS-CoV, le MERS-CoV ou un virus de l'influenza qui présentaient un trouble respiratoire grave. Pour l'évaluation de l'innocuité, nous avons également tenu compte de données recueillies chez des patients infectés par le virus Ebola. Nous nous sommes servis de la définition de l'Organisation mondiale de la Santé en ce qui a trait à la COVID-19 et à l'atteinte respiratoire grave, soit une fièvre ou une infection respiratoire soupçonnée accompagnée d'au moins 1 des symptômes suivants : fréquence respiratoire supérieure à 30 respirations par minute, détresse respiratoire importante, ou saturation périphérique en oxygène $\left(\mathrm{SpO}_{2}\right)$ de $93 \%$ ou moins à l'air ambiant ${ }^{16}$. Les études admissibles devaient comparer l'administration intraveineuse de plasma de convalescent ou d'immunoglobulines hyperimmunes à une prise en charge classique sans administration de plasma de convalescent.

Les paramètres à l'étude comprenaient la mortalité au suivi le plus éloigné, le stade de rétablissement, la durée du séjour aux soins intensifs, la durée d'hospitalisation, le nombre de jours sous ventilation mécanique et la charge virale. Nous avons également recueilli des données sur la survenue d'événements indésirables graves, comme les complications liées à une surcharge volémique intravasculaire, les lésions pulmonaires aiguës post-transfusionnelles, les réactions allergiques ou anaphylactiques et autres.

Pour chaque population de patients, nous n'avons retenu que des ERC lorsque c'était possible et avons tenu compte des bénéfices et des préjudices de façon satisfaisante. Si aucun ERC n'était disponible ou si des études contrôlées non randomisées fournissaient des renseignements complémentaires importants, nous avons retenu les études non randomisées comportant des analyses où les données étaient ajustées. En l'absence de ce type d'études, nous avons retenu les études non randomisées accessibles. Les études sans groupe témoin ont été exclues.

\section{Sources des données et recherches}

Aidés d'une bibliothécaire spécialisée en médecine (R.C.), nous avons interrogé des bases de données en santé (MEDLINE, Embase, PubMed - pour les études non indexées - et le Cochrane Central Register of Controlled Trials [CENTRAL]) le 6 mars, puis de nouveau le 19 avril. Nous avons également interrogé medRxiv - pour les sources prépubliées non évaluées par les pairs - le 11 mars et le 26 avril, des bases de données chinoises (China National Knowledge Infrastructure [CNKI], Wanfang, Chongqing VIP Information [CQVIP] et SinoMed) le 23 mars et le 21 avril, et ChinaXiv le 26 avril 2020. Nous nous sommes servis de mots-clés anglais en lien avec les virus (" coronavirus », « influenza », "Ebola », " MERS », «SARS ») et en lien avec les interventions (« convalescent plasma », « hyperimmune plasma »). 


\section{Entrée du SRAS-CoV-2 dans une cellule hôte}
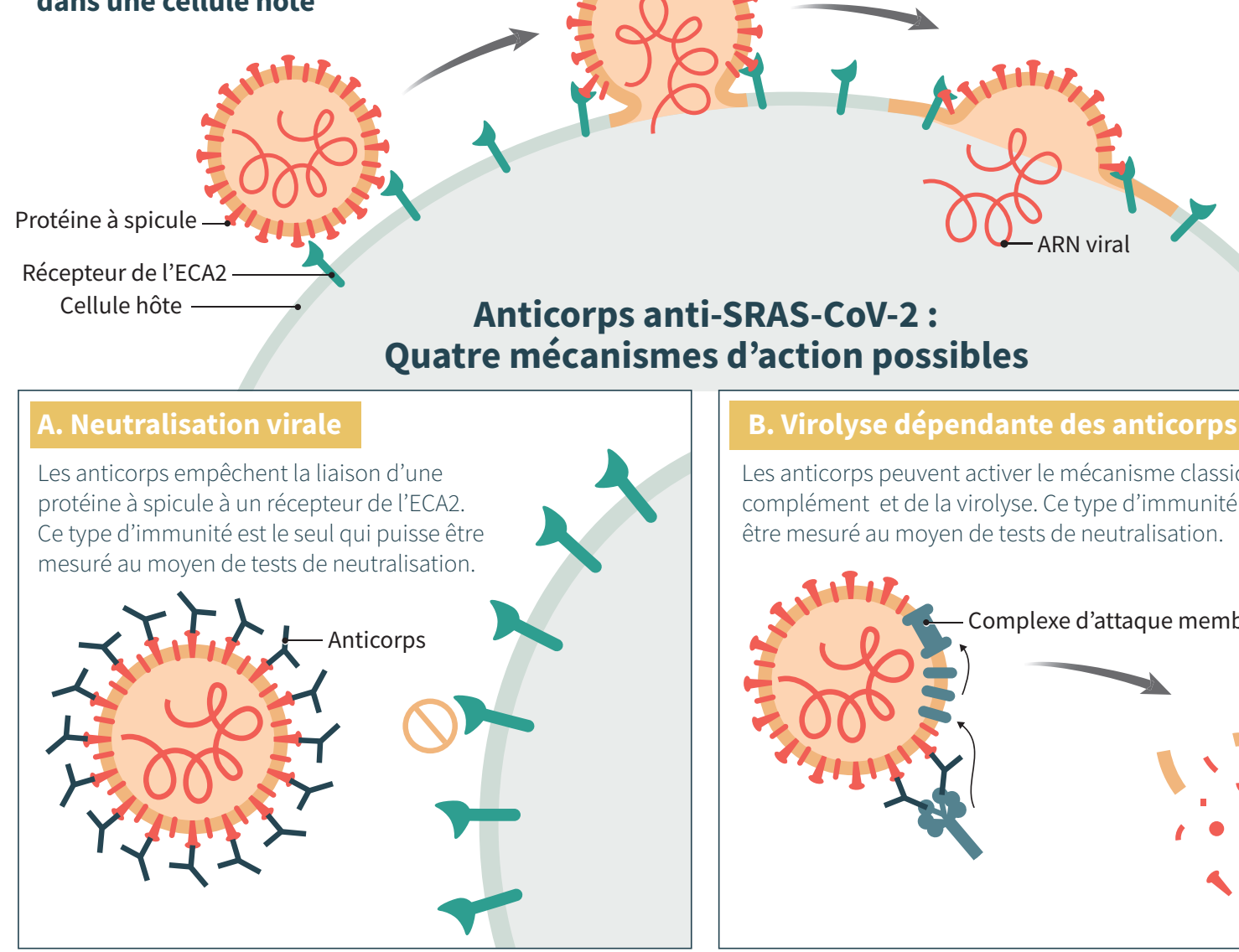

\section{B. Virolyse dépendante des anticorps}

Les anticorps peuvent activer le mécanisme classique du complément et de la virolyse. Ce type d'immunité ne peut pas être mesuré au moyen de tests de neutralisation.

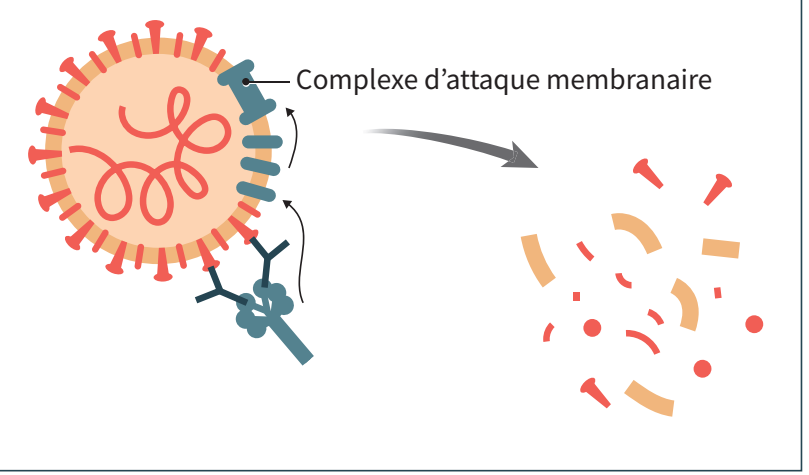

\section{Présentation antigénique médiée par les anticorps}

Les anticorps se lient aux particules virales, ce qui stimule les cellules présentatrices d'antigène et active une réponse immunitaire à médiation cellulaire. Ce type d'immunité ne peut pas être mesuré au moyen de tests de neutralisation.

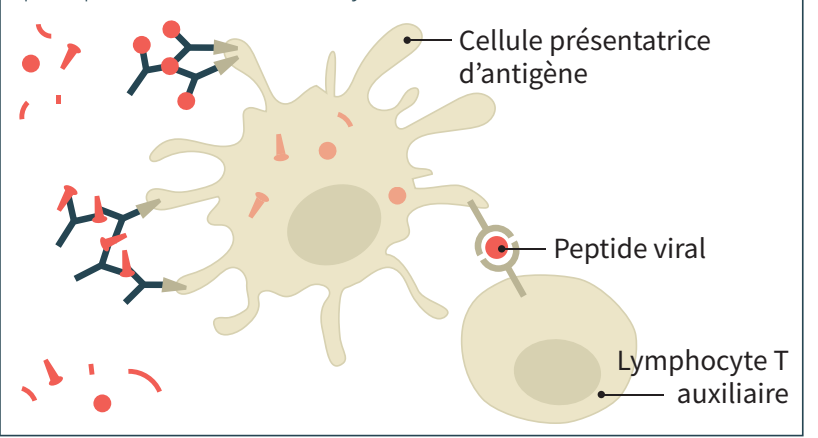

\section{Cytotoxicité dépendante des anticorps}

Les anticorps se trouvant à la surface de la cellule infectée permettent aux cellules tueuses naturelle de la repérer et de la détruire. Ce type d'immunité ne peut pas être mesuré au moyen de tests de neutralisation.

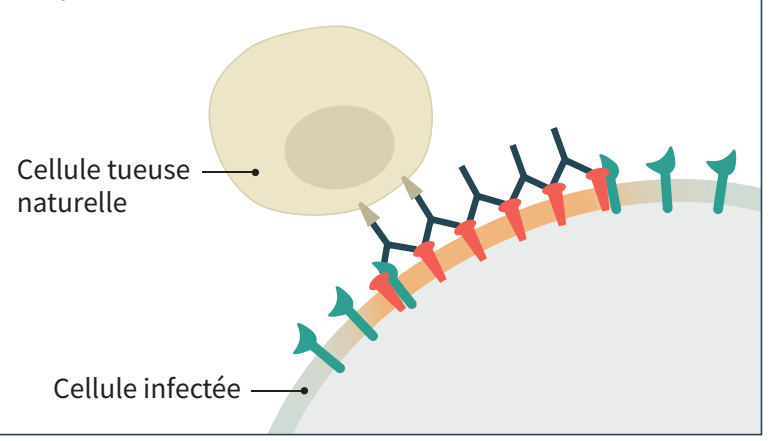

Figure 1 : Mécanismes d'action possibles des anticorps contre le coronavirus du syndrome respiratoire aigu sévère 2 (SRAS-CoV-2) en cas de maladie à coronavirus 2019 (COVID-19). Cette figure illustre le mécanisme normal d'entrée du SRAS-CoV-2 dans une cellule hôte, au cours duquel la fusion membranaire est induite par l'interaction entre les glycoprotéines à spicules du SRAS-CoV-2 (en rouge) et les récepteurs de l'enzyme de conversion de l'angiotensine 2 (ECA2) [en vert] de la cellule hôte, interaction qui se produit au niveau de la membrane plasmique ou d'une membrane endosomique. Les anticorps dirigés contre le domaine de liaison au récepteur (DLR) des glycoprotéines à spicules peuvent empêcher l'interaction des spicules avec les récepteurs de l'ECA2, prévenant ainsi la pénétration du virus dans la cellule (A). Les anticorps dirigés contre les épitopes du DLR peuvent également avoir un effet antiviral par d'autres mécanismes (B, C et D). On ignore l'importance relative du rôle que pourraient jouer ces diverses fonctions dans le traitement d'une infection active au SRAS-CoV-2. Fait important, les tests de neutralisation généralement utilisés pour qualifier les produits hyperimmuns ne mesurent qu'un seul de ces 4 mécanismes et ne font pas nécessairement de liens avec les autres. 
Aucune restriction de langue n'a été imposée. L'annexe 1 présente la stratégie de recherche complète et résume les résultats obtenus.

Deux personnes ont évalué de façon indépendante les titres et les résumés des articles recensés, puis le texte intégral des articles potentiellement admissibles. Elles ont également examiné les références des articles admissibles à la recherche d'autres études pertinentes.

\section{Extraction des données et évaluation de la qualité}

Deux personnes ont extrait, de façon indépendante, les données relatives à l'étude, aux caractéristiques des participants, à la technique de prélèvement du plasma, à la méthode de quantification des anticorps du plasma de convalescent ou hyperimmun, aux paramètres de l'étude et au risque de biais, puis elles les ont compilés dans des chiffriers Excel. Tout désaccord a été réglé par la discussion.

Une version modifiée de l'outil Cochrane d'évaluation des risques de biais a été utilisée pour évaluer les $E R C^{17}$. Elle mettait en évidence 6 possibles sources de biais : la génération des séquences d'attribution, la dissimulation de l'attribution des traitements, l'insu, la perte au suivi, la déclaration sélective des résultats et d'autres problèmes. Pour l'évaluation des études de cohortes contrôlées, nous avons utilisé une version modifiée de l'outil Newcastle-Ottawa ${ }^{18}$, qui nous a permis de relever les sources possibles de biais en lien avec la sélection des participants, la relation temporelle entre l'exposition et les résultats, la mesure des résultats, l'exposition et les facteurs pronostiques, l'équilibre des facteurs pronostiques, l'équilibre des traitements concomitants entre les groupes et l'exhaustivité du suivi. Dans les 2 outils, les réponses possibles pour chaque élément étaient « absolument » et " probablement » (faible risque de biais), ainsi que " probablement pas » et «certainement pas » (risque élevé de biais). Nous avons déterminé que le risque global de biais de chaque paramètre d'une étude donnée était faible si tous les éléments pertinents comportaient un faible risque de biais, et élevé dans tous les autres cas. Pour en savoir plus à ce sujet, consulter le https://www.evidencepartners.com/ resources/methodological-resources/

\section{Qualité des données probantes}

Nous avons évalué la qualité des données probantes au moyen de l'approche GRADE (Grading of Recommendations Assessment, Development, and Evaluation $)^{19}$, en tenant compte du risque de biais, du caractère indirect, non uniforme ou imprécis des études, le cas échéant, et du risque de biais de publication. Le niveau de qualité des données est présenté dans les tableaux résumant les résultats ${ }^{20,21}$.

\section{Analyse des données}

Le modèle à effets aléatoires de DerSimonian et Laird a été utilisé pour calculer le risque relatif (RR) des paramètres binaires et le rapport de cotes $(\mathrm{RC})$ proportionnel des paramètres ordinaux. Les intervalles de confiance (IC) ont été fixés à $95 \%$. Pour les paramètres continus, nous avons calculé les différences moyennes (DM) pondérées à l'aide du modèle à effets aléatoires de
DerSimonian et Laird. Aux fins de compilation des résultats, nous avons estimé les moyennes et les écarts-types des études qui déclaraient plutôt des médianes et des écarts interquartiles. Pour ce faire, nous avons utilisé la formule suivante ${ }^{22}$ : $\left(75^{\mathrm{e}}\right.$ percentile $25^{\mathrm{e}}$ percentile) / 1,35. Nous avons aussi regroupé les effets estimés pour chaque groupe de population par type de virus. Comme nous nous attendions à un petit nombre d'études, nous n'avons pas fait de diagramme en entonnoir ni de tests statistiques pour évaluer le risque de biais de publication, et n'avons pas formulé d'hypothèses quant aux effets par sous-groupes. Pour calculer la différence des risques (DR) avec un IC de 95\%, nous avons appliqué les RR et les RC regroupés aux estimations du risque de référence tirées des études sur la COVID-1933; lorsque cela n'était pas possible, nous les avons appliqués au risque de référence médian des groupes témoins des études admissibles. Toutes les analyses ont été faites à l'aide du logiciel Stata 15.

\section{Approbation éthique}

Une approbation éthique n'était pas requise pour cette revue systématique.

\section{Résultats}

La recherche documentaire a permis de récupérer 1099 articles après l'élimination des doublons. Le diagramme de l'approche PRISMA (figure 2) présente les raisons pour lesquelles des études ont été exclues après la lecture de l'article intégral. Aucune étude admissible sur la COVID-19 n'a été recensée. Six études ${ }^{23-28}$ étaient admissibles (tableau 1), dont 4 ERC portant sur des patients ayant contracté le virus de l'influenza ${ }^{24-27}$. Une étude non randomisée sur le SRAS-CoV ${ }^{23}$ a fourni des données sur l'efficacité du plasma de convalescent, tandis que des ERC sur l'influenza ${ }^{24-27}$ et des études non randomisées sur l'Ebola ${ }^{28}$ et le SRAS- $\mathrm{CoV}^{23}$ ont fourni des données sur son innocuité.

Parmi les 4 ERC retenus, 3 ont été menés à l'insu des patients et des médecins ${ }^{24,26,27}-2$ administrant au groupe témoin une solution intraveineuse contenant un faible titre d'immunoglobulines ${ }^{24,26}$, et 1 administrant une solution physiologique salée ${ }^{27}-$, et 1 était ouvert ${ }^{25}$. Le tableau 2 présente le risque de biais associé au taux de mortalité et à la durée d'hospitalisation. Tous les ERC sauf $1^{25}$ avaient un faible risque de biais (tableau 2).

La méthode utilisée pour prélever le sérum hyperimmun variait d'un ERC à l'autre. Seuls Hung et ses collaborateurs ${ }^{24}$ ont recueilli du plasma de donneurs récemment rétablis (dans les 2 semaines précédentes) et ont quantifié l'activité des anticorps en mesurant les titres d'anticorps neutralisants. Les 3 autres essais ${ }^{25-27}$ ont obtenu du plasma de banques de sang et se sont servis du plasma de donneurs présentant des titres élevés d'anticorps au test d'inhibition de l'hémagglutination (IHA) plutôt que de donneurs s'étant récemment rétablis. Les 3 ERC ont fait état de titres très élevés (tableau 1 ).

\section{Mortalité}

En ce qui concerne le SRAS-CoV, une petite étude contrôlée non randomisée a montré que l'existence d'un effet du plasma de convalescent sur la mortalité était incertaine, selon les estimations 


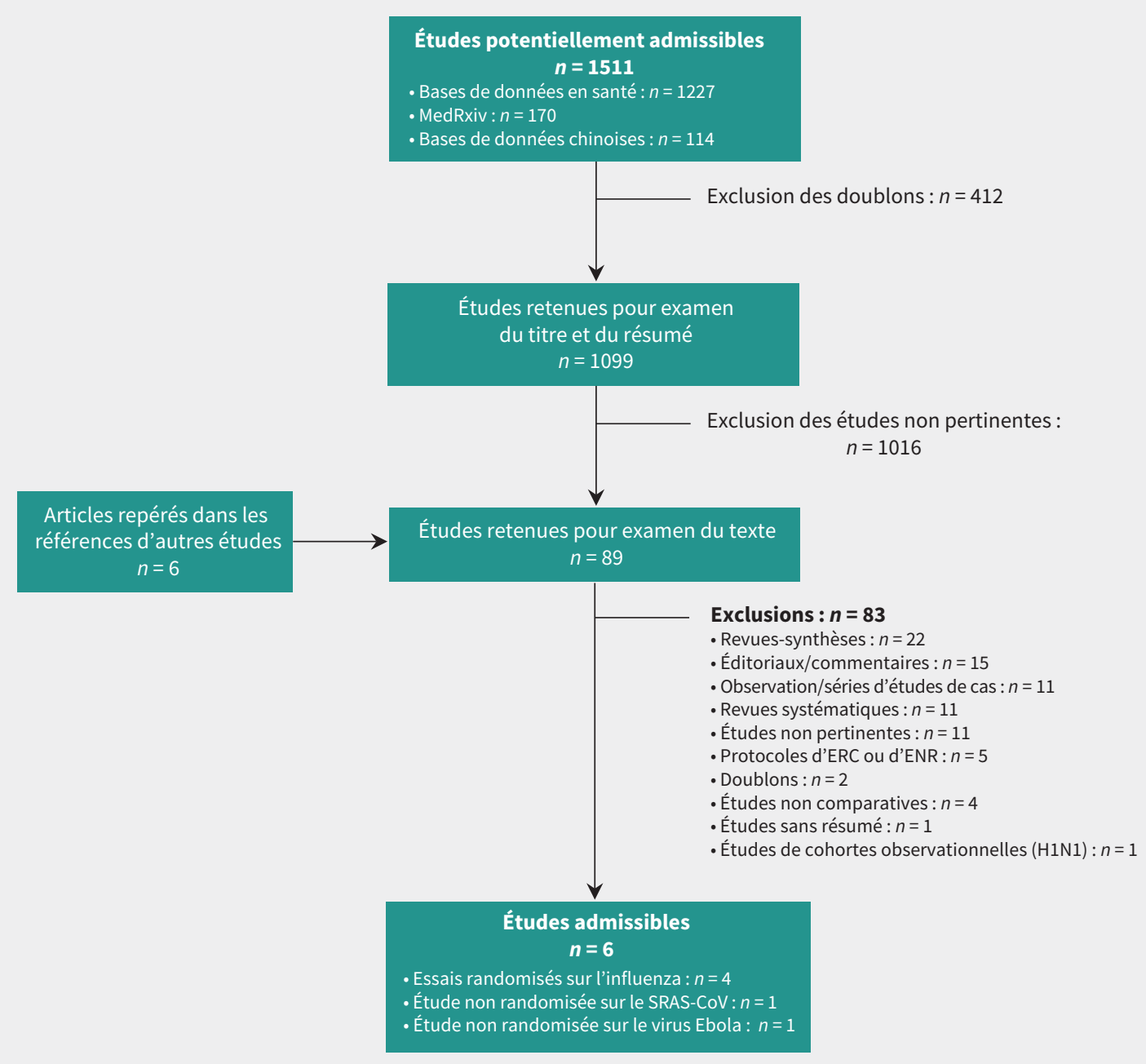

Figure 2 : Diagramme du processus de sélection des études. Remarque : ENR = essai non randomisé, ERC = essai randomisé et contrôlé, SRAS-CoV = coronavirus du syndrome respiratoire aigu sévère.

non ajustées (RR : 0,10; IC de $95 \%$ : 0,01 à 1,70; données de très faible qualité) ${ }^{23}$ [figure 3 et tableau 3].

Quatre ERC portant sur des patients atteints d'une forme grave de l'influenza ( $n=572$ ) ont donné des résultats non concluants quant à l'effet du plasma de convalescent sur la mortalité entre les jours 7 et 28 (RR 0,94; IC de $95 \% 0,49$ à 1,80; données de très faible qualité) [figure 3 et tableau 3]. Deux ERC sur des patients ayant contracté l'influenza ont fourni des données sur 6 paramètres possibles en lien avec le stade de rétablissement au jour 28 (décès, hospitalisation aux soins intensifs, hospitalisation avec oxygénothérapie, hospitalisation sans oxygénothérapie, congé et rétablissement incomplet, congé et rétablissement complet) ${ }^{25-27}$. Le $\mathrm{RC}$ regroupé pour le rétablissement (438 patients de deux $\mathrm{ERC}^{26,27}$ ) était de 1,05 (IC de $95 \%$ 0,67 à 1,64$)$, ce qui témoigne de données de très faible qualité (figure 4 et tableau 3).

\section{Durée d'hospitalisation et de séjour aux soins intensifs} Trois $\mathrm{ERC}^{24-26}$ portant sur des cas graves d'influenza ont indiqué qu'il est possible, mais incertain, que le plasma de convalescent réduise la durée d'hospitalisation (DM pondérée -1,62 jour; IC de $95 \%-3,82$ à 0,58 jours), le séjour aux soins intensifs (DM pondérée $-0,32$ jour; IC de $95 \%-3,20$ à 2,56 jours) et la durée de la ventilation mécanique (DM pondérée -3,67 jours; IC de 95\%-7,70 à 0,36 jours). Tous ont fourni des données de très faible qualité (figure 5 et tableau 3).

\section{Réduction de la charge virale}

Les estimations regroupées de $2 \mathrm{ERC}^{25,27}$ menés auprès de patients atteints d'une forme grave de l'influenza $(n=334)$ n'ont pas permis de conclure que le plasma de convalescent changeait la proportion de patients chez qui le virus n'est plus détectable dans des prélèvements nasopharyngés au jour 3 (RR 1,07 ; IC de $95 \%$ 0,58 à 1,8; données de très faible qualité) et ont indiqué qu'il est possible, mais incertain, qu'il augmente le nombre de patients chez qui le virus n'est plus détectable au jour 725 (RR 1,32; IC de $95 \%$ 0,97 à 1,81; données de très faible qualité). 


\begin{tabular}{|c|c|c|c|c|c|c|c|c|}
\hline $\begin{array}{l}\text { Étude, } \\
\text { année et } \\
\text { pays }\end{array}$ & $\begin{array}{l}\text { Modèle } \\
\text { d'étude }\end{array}$ & Maladie & Intervention & Comparateurs & $\begin{array}{l}\text { Taille de } \\
\text { l'échantillon }\end{array}$ & $\begin{array}{l}\text { Âge médian } \\
(\text { (EI)*, en } \\
\text { années }\end{array}$ & $\begin{array}{l}\text { Système de } \\
\text { classification } \\
\text { de l'USI, score } \\
\text { médian (EI) }\end{array}$ & $\begin{array}{c}\text { Temps écoulé } \\
\text { depuis } \\
\text { l'apparition des } \\
\text { symptômes, } \\
\text { médiane (EI), } \\
\text { en jours }\end{array}$ \\
\hline $\begin{array}{l}\text { Soo et coll., } \\
2004{ }^{23} \\
\text { Hong Kong }\end{array}$ & $\begin{array}{l}\text { Étude de } \\
\text { cohortes } \\
\text { rétrospective }\end{array}$ & $\begin{array}{l}\text { SRAS-CoV } \\
\text { - patients } \\
\text { hospitalisés }\end{array}$ & $\begin{array}{l}\text { Administration de } \\
200 \text { à } 400 \mathrm{~mL} \text { de } \\
\text { PC (titre } \\
1: 160-1: 2560)\end{array}$ & $\begin{array}{l}\text { Méthylprednisolone } \\
\text { ( } \geq 4 \text { doses de } \\
500 \text { mg par } \\
\text { thérapie pulsée) }\end{array}$ & $\begin{array}{l}\text { Groupe } \mathrm{PC}: \\
n=19 \\
\text { Groupe témoin: } \\
n=21\end{array}$ & $\begin{array}{l}\text { Groupe PC: } \\
\text { moyenne } 38,7 \\
(\mathrm{ET}: 12,39) \\
\text { Groupe témoin: } \\
\text { moyenne } 47,9 \\
(\mathrm{ET}: 19,6)\end{array}$ & ND & ND \\
\hline $\begin{array}{l}\text { Hung } \\
\text { et coll., } \\
2013{ }^{24} \\
\text { Hong Kong }\end{array}$ & ERC & $\begin{array}{l}\text { Influenza } \\
\text { H1N1 } \\
\text { - patients } \\
\text { hospitalisés }\end{array}$ & $\begin{array}{l}\text { Perfusion unique } \\
\text { d'IgIV } \mathrm{H} \text {, à raison } \\
\text { de } 0,4 \mathrm{~g} / \mathrm{kg} \text {, } \\
\text { pendant } 4 \mathrm{~h} \text {; titre } \\
\text { d'ACN > 1:40 }\end{array}$ & $\begin{array}{l}0,4 \mathrm{~g} / \mathrm{kg} \text { d'IIgIV } \\
\text { normales } \\
\text { préparées par la } \\
\text { pharmacie; titre } \\
\text { d'AcN }<1: 10\end{array}$ & $\begin{array}{l}\text { Groupe PC: } \\
n=17 \\
\text { Groupe témoin: } \\
n=18\end{array}$ & $\begin{array}{l}\text { Groupe PC: } \\
43 \text { ( } 36,5 \text { à } 56) \\
\text { Groupe témoin : } \\
52(40,5 \text { à } 58,5)\end{array}$ & $\begin{array}{l}\text { APACHE II; } \\
\text { Groupe PC: } \\
12 \text { (8 à 17,5) } \\
\text { Groupe témoin: } \\
13 \text { (9 à 19) }\end{array}$ & $\begin{array}{l}\text { Groupe PC: } \\
2 \text { (1 à 4) } \\
\text { Groupe témoin : } \\
3 \text { (2 à 5) }\end{array}$ \\
\hline $\begin{array}{l}\text { Beigel } \\
\text { et coll., } \\
2019,,^{26} \text { US }\end{array}$ & ERC & $\begin{array}{l}\text { Influenza A } \\
\text { (H1N1, H3N2) } \\
\text { - patients } \\
\text { hospitalisés }\end{array}$ & $\begin{array}{l}\text { Perfusion de } \\
2 \text { unités de plasma } \\
\text { à titre élevé } \\
\text { d'anticorps contre } \\
\text { l'influenza (titre au } \\
\text { test d'inhibition de } \\
\text { l'hémagglutination } \\
\geq 1: 80 \text { ) }\end{array}$ & $\begin{array}{l}\text { Perfusion de } \\
2 \text { unités de plasma } \\
\text { à faible titre } \\
\text { d'anticorps contre } \\
\text { l'influenza (titre au } \\
\text { test d'inhibition de } \\
\text { l'hémagglutination } \\
\leq 1: 10 \text { ) }\end{array}$ & $\begin{array}{l}\text { Groupe PC: } \\
n=91 \\
\text { Groupe témoin: } \\
n=47\end{array}$ & $\begin{array}{l}\text { Groupe PC: } \\
43 \text { ( } 36,5 \text { à } 56) \\
\text { Groupe témoin: } \\
52 \text { (40,5 à } 58,5)\end{array}$ & $\begin{array}{l}\text { NEWS; } \\
\text { Groupe PC: } \\
5 \text { (4 à 8) } \\
\text { Groupe témoin: } \\
5 \text { ( } 3 \text { à } 7) \\
\text { Score PELOD; } \\
\text { Groupe PC: } \\
0 \text { (0 à 1) } \\
\text { Groupe témoin: } \\
3 \text { (1,5 à } 12)\end{array}$ & $\begin{array}{l}\text { Groupe PC: } \\
3 \text { (2 à 5) } \\
\text { Groupe témoin: } \\
3 \text { (2 à 4) }\end{array}$ \\
\hline $\begin{array}{l}\text { Davey } \\
\text { et coll., } \\
2019,{ }^{27} \\
\text { multi- } \\
\text { national }\end{array}$ & ERC & $\begin{array}{l}\text { Influenza A } \\
\text { (H1N1, H3N2), } \\
\text { influenza B } \\
\text { - patients } \\
\text { hospitalisés }\end{array}$ & $\begin{array}{l}\text { Perfusion unique } \\
\text { d'IglV-H, à raison } \\
\text { de } 0,25 \mathrm{~g} / \mathrm{kg} \\
\text { (maximum de } \\
24,75 \mathrm{~g} \text { ) dans un } \\
\text { sac de } 500 \mathrm{~mL} \text { de } \\
\text { solution } \\
\text { physiologique } \\
\text { salée, pendant } 2 \mathrm{~h}\end{array}$ & $\begin{array}{l}\text { Perfusion d'un sac } \\
\text { de } 500 \mathrm{~mL} \text { de } \\
\text { solution } \\
\text { physiologique } \\
\text { salée placé dans } \\
\text { une pochette } \\
\text { colorée }\end{array}$ & $\begin{array}{l}\text { Groupe PC: } \\
n=156 \\
\text { Groupe témoin: } \\
n=152\end{array}$ & $\begin{array}{l}\text { Groupe PC : } 55 \\
\text { (41 à 68) } \\
\text { Groupe témoin: } \\
57 \text { (48 à 68) }\end{array}$ & $\begin{array}{l}\text { NEWS; } \\
\text { Groupe PC: } \\
4 \text { (2 à 6) } \\
\text { Groupe témoin: } \\
4 \text { (2 à 6) }\end{array}$ & $\begin{array}{l}\text { Groupe PC: } \\
3 \text { (2 à 5) } \\
\text { Groupe témoin : } \\
4 \text { (2 à 5) }\end{array}$ \\
\hline
\end{tabular}

Remarque : $\mathrm{AcN}=$ anticoprs neutralisants, $\mathrm{APACHE} \mathrm{II}=$ Acute Physiologic Assessment and Chronic Health Evaluation II, EI = écart interquartile, ERC = essai randomisé et contrôlé, $\mathrm{ET}=$ écart-type, IgIV = immunoglobulines intraveineuses, IgIV-H = immunoglobulines intraveineuses hyperimmunes, ND = non déclaré, NEWS = National Early Warning Score, PC = plasma de convalescent, PELOD = Pediatric Logistic Organ Dysfunction, SRAS-CoV = coronavirus du syndrome respiratoire aigu sévère, USI = unité de soins intensifs.

*Sauf mention contraire.

\section{Préjudices}

Les estimations regroupées des $4 \mathrm{ERC}^{24-27}$ sur des cas graves d'influenza $(n=576)$ ont indiqué que le plasma de convalescent n'avait causé que peu d'événements indésirables graves, voire aucun (RR 0,85; IC de $95 \%$ 0,56 à 1,29; données de faible qualité) [figure 6 et tableau 3]. Deux ERC ${ }^{25,26}$ ont signalé des réactions transfusionnelles indésirables graves chez 8 (6\%) des 140 patients du groupe d'intervention, comparativement à $6(6 \%)$ des 96 patients du groupe témoin. Les études non randomisées portant sur des patients infectés par le SRAS-CoV ${ }^{23}$ ou le virus Ebola ${ }^{28}$ et 1 ERC sur des patients ayant l'influenza ${ }^{24}$ n'ont rapporté aucun événement indésirable grave lié à une surcharge volémique intravasculaire, à une lésion pulmonaire aiguë post-transfusionnelle ou à une réaction allergique grave provoquée par la transfusion de plasma.

\section{Interprétation}

Les études recensées n'ont fourni que des données de très faible qualité sur les bénéfices associés au plasma de convalescent chez les personnes atteintes de la COVID-19. Toutefois, si l'on se fie aux données de faible qualité, rien ne laisse croire que le plasma de convalescent provoquerait des événements indésirables graves chez ces personnes.

Le 25 mars 2020, la Food and Drug Administration des ÉtatsUnis a approuvé l'utilisation d'urgence du plasma de convalescent comme traitement expérimental en cas de COVID-19, mais pas son utilisation clinique systématique ${ }^{29}$. Son inclusion au programme d'accès élargi ne devrait pas être interprétée comme un gage d'efficacité, le programme ayant comme critère le manque 
Tableau 2 : Risque de biais d'évaluation pour le taux de mortalité et la durée d'hospitalisation, estimé au moyen d'une version modifiée des critères pour les essais cliniques randomisés et les études non randomisées

\begin{tabular}{|c|c|c|c|c|c|c|c|c|}
\hline $\begin{array}{l}\text { Essais sur } \\
\text { l'influenza, } \\
\text { mortalité }\end{array}$ & $\begin{array}{l}\text { Génération } \\
\text { des } \\
\text { séquences } \\
\text { d'attribution }\end{array}$ & $\begin{array}{c}\text { Dissimulation } \\
\text { de l'attribution } \\
\text { des } \\
\text { traitements }\end{array}$ & $\begin{array}{c}\text { Insu } \\
\text { (patients) }\end{array}$ & $\begin{array}{c}\text { Insu } \\
\text { (fournisseurs } \\
\text { de soins) }\end{array}$ & $\begin{array}{c}\text { Insu } \\
\text { (évaluateurs } \\
\text { des résultats) }\end{array}$ & $\begin{array}{l}\text { Insu } \\
\text { (responsables } \\
\text { de la collecte } \\
\text { de données) }\end{array}$ & $\begin{array}{c}\text { Insu } \\
\text { (analystes } \\
\text { des données) }\end{array}$ & Perte au suivi \\
\hline Beigel et coll., $2017^{25}$ & Absolument & Absolument & Absolument & $\begin{array}{l}\text { Absolument } \\
\text { pas }\end{array}$ & $\begin{array}{c}\text { Probablement } \\
\text { pas }\end{array}$ & Absolument & $\begin{array}{l}\text { Probablement } \\
\text { pas }\end{array}$ & $\begin{array}{l}\text { Absolument } \\
\text { pas }\end{array}$ \\
\hline Beigel et coll., $2019^{26}$ & Absolument & Absolument & Absolument & Absolument & Absolument & Absolument & Absolument & Probablement \\
\hline Davey et coll., $2019^{27}$ & Absolument & Absolument & Absolument & Absolument & Absolument & Absolument & Absolument & Absolument \\
\hline Hung et coll., $2013^{24}$ & Absolument & Absolument & Absolument & Absolument & Absolument & Absolument & Absolument & Absolument \\
\hline $\begin{array}{l}\text { Étude non } \\
\text { randomisée sur le } \\
\text { SRAS-CoV, mortalité }\end{array}$ & $\begin{array}{l}\text { Sélection des } \\
\text { groupes }\end{array}$ & $\begin{array}{l}\text { Évaluation de } \\
\text { l'exposition }\end{array}$ & $\begin{array}{l}\text { Paramètre } \\
\text { suite à } \\
\text { l'exposition }\end{array}$ & $\begin{array}{l}\text { Comparabilité } \\
\text { aux valeurs de } \\
\text { référence }\end{array}$ & $\begin{array}{l}\text { Mesure des } \\
\text { variables } \\
\text { pronostiques }\end{array}$ & $\begin{array}{c}\text { Évaluation des } \\
\text { paramètres }\end{array}$ & $\begin{array}{l}\text { Exhaustivité } \\
\text { du suivi }\end{array}$ & $\begin{array}{l}\text { Traitements } \\
\text { concomitants }\end{array}$ \\
\hline Soo et coll., $2004^{23}$ & $\begin{array}{l}\text { Absolument } \\
\text { pas }\end{array}$ & Probablement & Absolument & $\begin{array}{l}\text { Absolument } \\
\text { pas }\end{array}$ & $\begin{array}{l}\text { Absolument } \\
\text { pas }\end{array}$ & $\begin{array}{l}\text { Absolument } \\
\text { pas }\end{array}$ & $\begin{array}{l}\text { Absolument } \\
\text { pas }\end{array}$ & $\begin{array}{l}\text { Absolument } \\
\text { pas }\end{array}$ \\
\hline $\begin{array}{l}\text { Essais sur } \\
\text { l'influenza, durée } \\
\text { d'hospitalisation }\end{array}$ & $\begin{array}{l}\text { Génération } \\
\text { des } \\
\text { séquences } \\
\text { d'attribution }\end{array}$ & $\begin{array}{l}\text { Dissimulation } \\
\text { de l'attribution } \\
\text { des traitements }\end{array}$ & $\underset{\text { Insu }}{\text { (patients) }}$ & $\begin{array}{l}\text { Insu } \\
\text { (fournisseurs } \\
\text { de soins) }\end{array}$ & $\begin{array}{c}\text { Insu } \\
\text { (évaluateurs } \\
\text { des résultats) }\end{array}$ & $\begin{array}{l}\text { Insu } \\
\text { (responsables } \\
\text { de la collecte } \\
\text { de données) }\end{array}$ & $\begin{array}{c}\text { Insu } \\
\text { (analystes des } \\
\text { données) }\end{array}$ & Perte au suivi \\
\hline Beigel et coll., $2019^{26}$ & Absolument & Absolument & Absolument & Absolument & Absolument & Absolument & Absolument & Probablement \\
\hline Hung et coll., $2013^{24}$ & Absolument & Absolument & Absolument & Absolument & Absolument & Absolument & Absolument & Absolument \\
\hline Beigel et coll., $2017^{25}$ & Absolument & Absolument & Absolument & $\begin{array}{l}\text { Absolument } \\
\text { pas }\end{array}$ & $\begin{array}{c}\text { Probablement } \\
\text { pas }\end{array}$ & Absolument & $\begin{array}{l}\text { Probablement } \\
\text { pas }\end{array}$ & $\begin{array}{l}\text { Absolument } \\
\text { pas }\end{array}$ \\
\hline
\end{tabular}

Remarque : $E R C=$ essai randomisé et contrôlé, SRAS-CoV = coronavirus du syndrome respiratoire aigu sévère.

d'autres options thérapeutiques approuvées ou d'accès à des essais cliniques plutôt que l'efficacité avérée. Les données limitées sur les bénéfices - ou dans le cas qui nous intéresse, sur l'absence ou presque de bénéfices - d'une intervention n'ayant pas fait ses preuves sont-elles suffisantes pour en justifier l'utilisation par compassion? Cette question est matière à débat ${ }^{30}$.

Parmi les forces de cette revue systématique, notons la tenue de recherches exhaustives dans diverses bases de données pour y trouver des études passées et émergentes, ainsi que l'adoption de l'approche GRADE pour évaluer la qualité des données tout en portant attention au lien indirect entre les populations étudiées et les patients atteints de la COVID19. Les décisions quant à l'admissibilité des études, à l'évaluation du risque de biais et à l'extraction des données ont toutes été prises en tandem. Nous avons également limité le risque de biais en excluant les études portant sur un seul groupe.

Une revue systématique publiée en 2006 a résumé les données de 8 études d'observation contrôlées sur le plasma de convalescent ( $n=1703$ patients) menées durant la pandémie de grippe espagnole en $1918^{10}$. La DR absolue entre le taux de mortalité des patients ayant reçu du plasma de convalescent et celui des patients des groupes témoins allait de $8 \%$ à $26 \%$ (DR regroupée $21 \%$; IC de $95 \% 15 \%$ à $27 \%)^{10}$. Cependant, ces études d'observation, dans lesquelles les facteurs pronostiques étaient manifestement déséquilibrés, fournissaient uniquement des données de très faible qualité, même pour l'influenza; par conséquent, la qualité de ces données est encore plus faible lorsqu'on les applique à la COVID-19.
De même, une revue systématique de $2015^{6}$ a signalé une réduction très importante du taux de mortalité ( $\mathrm{RC} 0,25$; IC de $95 \% 0,14$ à 0,$45 ; l^{2}=0 \%$ ) dans le cadre d'une méta-analyse posthoc d'études d'observation $(n=8)$ sur l'administration de plasma de convalescent en cas de SRAS grave (une étude rétrospective de cohortes $^{23}$ et une série d'études de $\operatorname{cas}^{31}$ ) ou d'influenza A. Ici aussi, les données sont de très faible qualité, même pour le SRAS, et donc de qualité encore plus faible pour la COVID-19.

Une revue systématique récente ${ }^{32}$ non évaluée par des pairs parue sur un serveur de prépublication ${ }^{33}$ a regroupé les données de 5 ERC sur l'influenza, dont $4^{24-27}$ retenus pour la présente revue $^{32}$. Les estimations regroupées du taux de mortalité étaient très semblables à celles présentées dans notre revue, avec un $\mathrm{RC}$ de 1,06 (IC de $95 \%$ 0,51 à 2,23). Il faut cependant préciser que les auteurs ont inclus dans leur revue l'essai INSIGHT FLU005 $5^{34}$, un essai pilote de l'International Network for Strategic Initiatives in Global HIV Trials, comptant ainsi en double les patients qui ont participé à l'essai principal ${ }^{27}$. De plus, ils n'ont pas regroupé les données relatives au paramètre ordinal (stade de rétablissement), et n'ont pas utilisé l'approche GRADE pour évaluer la qualité des données probantes, qui est importante dans le cadre de notre revue parce qu'elle nous permet d'évaluer le caractère indirect de ces données.

Trois études portaient sur l'utilisation du plasma de convalescent en cas de forme grave de COVID-19. Une série d'études de cas $^{35}$ s'est penchée sur 5 patients gravement malades; 3 d'entre eux avaient obtenu leur congé et 2 avaient vu leur état s'améliorer après avoir reçu du plasma de convalescent. Une autre étude non contrôlée de phase 1 a fait état d'une amélioration clinique 


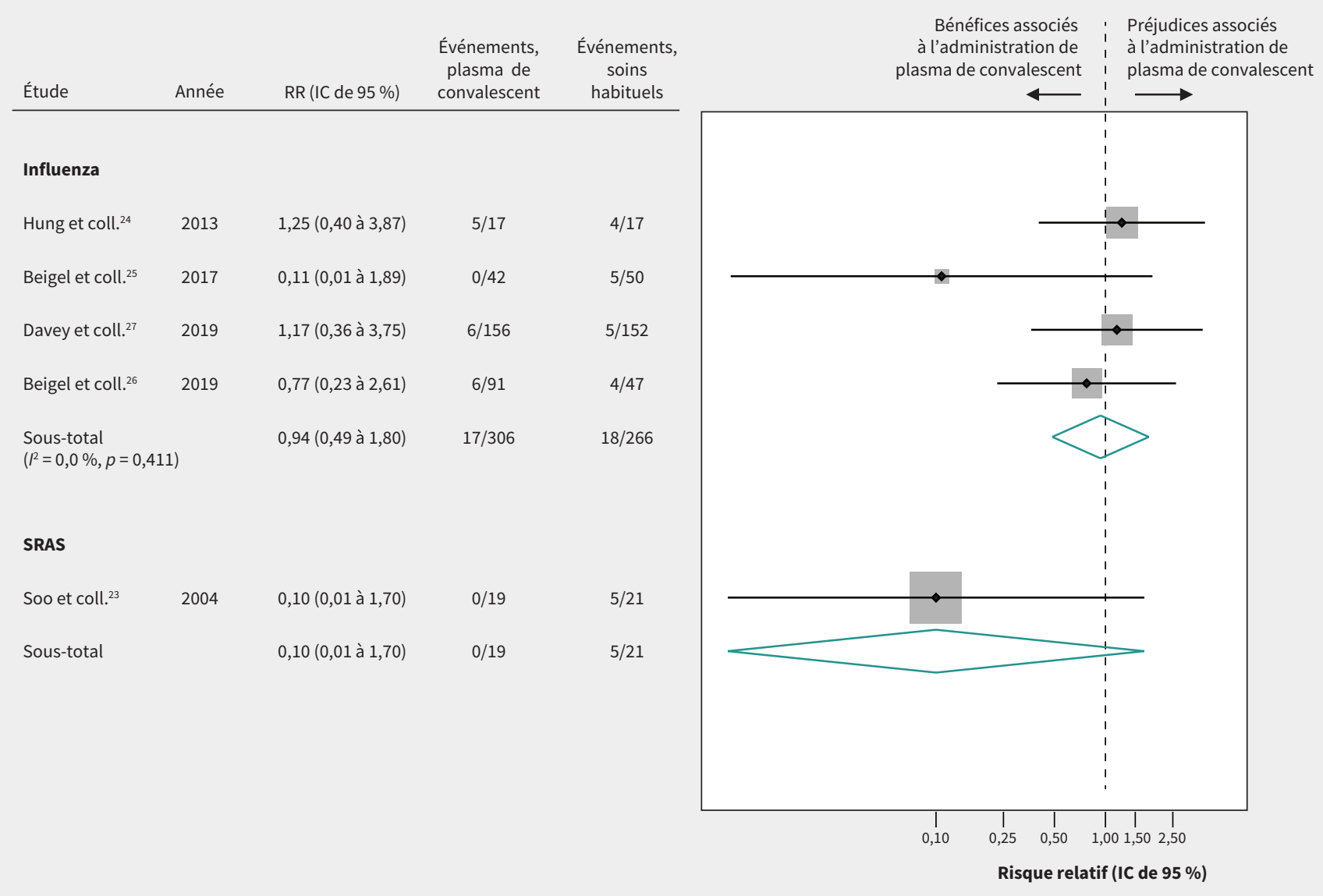

Figure 3 : Efficacité du plasma de convalescent sur la mortalité provoquée par les infections respiratoires aiguës virales. La pondération provient des analyses à effets aléatoires. Remarque : IC = intervalle de confiance, $R R=$ risque relatif, SRAS = syndrome respiratoire aigu sévère.

accompagnée de la guérison des lésions pulmonaires chez 10 patients atteints de la forme grave de la COVID-19 ayant reçu du plasma de convalescent ${ }^{36}$. Enfin, une série d'études de cas de 4 patients, dont 1 femme enceinte, a également signalé l'amélioration clinique de tous les sujets après la transfusion ${ }^{37}$. Ces séries d'études de cas non contrôlées ne permettent toutefois pas de remettre en question la conclusion de la présente étude, à savoir que les bénéfices associés au plasma de convalescent chez les patients atteints de la COVID-19 demeurent très incertains. Récemment, un traitement expérimental à base d'anticorps monoclonaux s'est montré prometteur pour réduire le taux de mortalité chez les personnes ayant contracté l'Ebola ${ }^{38}$. La généralisation des résultats de l'immunisation passive au moyen d'anticorps monoclonaux préparés selon des techniques hautement normalisées et soigneusement sélectionnés pour leur effet contre le virus de la COVID-19 est, au mieux, très discutable.

\section{Limites de l'étude}

L'une des principales limites de la présente revue découle du caractère indirect de cette dernière, les données provenant, pour la plupart, d'essais sur l'influenza. Bien qu'il s'agisse des meilleures données disponibles en ce moment d'urgence, les dif- férences entre les caractéristiques biologiques, cliniques et épidémiologiques de l'influenza et de la COVID-19 limitent grandement notre capacité à tirer des conclusions sur les effets du plasma de convalescent contre le nouveau coronavirus. La réponse immunitaire en 2 phases uniquement observée chez les patients atteints de la forme grave d'un coronavirus a une incidence directe sur les effets potentiels des stratégies de renforcement du système immunitaire ${ }^{39}$. Par ailleurs, le petit nombre d'études et d'événements relevés a donné lieu à de très grands intervalles de confiance, réduisant ainsi davantage la qualité des données. Enfin, comme les études d'observation pourraient fournir des preuves supplémentaires de préjudices, la restriction aux essais randomisés sur l'influenza constitue une limite.

Autre limite : le type de plasma utilisé explique possiblement le manque d'efficacité observé dans les essais sur l'influenza. Un seul essai ${ }^{24}$ portait sur l'utilisation de plasma de personnes s'étant rétablies de l'influenza dans les 2 semaines précédentes. Les chercheurs des autres essais ${ }^{25-27}$ ont dit avoir utilisé du plasma hyperimmun et ont signalé des titres très élevés au test d'IHA ${ }^{25-27}$. Toutefois, le recours à ce test pour quantifier l'activité des anticorps des donneurs de plasma s'avère controversé ${ }^{40}$. Les personnes qui sont d'avis que l'utilité du test d'IHA est limitée pourraient avancer que 3 des 
Patients ou population : enfants et adultes atteints d'une forme grave de COVID-19

Intervention : immunoglobulines intraveineuses de convalescent ou hyperimmunes

Comparaison : soins habituels + placebo (solution physiologique salée ou immunoglobulines intraveineuses)

\begin{tabular}{|c|c|c|c|c|c|}
\hline \multirow[b]{2}{*}{ Résultat } & \multirow[b]{2}{*}{$\begin{array}{c}\text { Effets relatifs, source des } \\
\text { données }\end{array}$} & \multicolumn{2}{|c|}{ Effets absolus } & \multirow[b]{2}{*}{$\begin{array}{l}\text { Certitude/qualité des } \\
\text { données }\end{array}$} & \multirow[b]{2}{*}{ Résumé simple } \\
\hline & & $\begin{array}{l}\text { Risque de } \\
\text { référence du } \\
\text { groupe } \\
\text { témoin } \\
\text { (pour 1000) }\end{array}$ & $\begin{array}{l}\text { Différence } \\
\text { (IC de } 95 \% \text { ) }\end{array}$ & & \\
\hline Mortalité (jours 7 et 28) & $\begin{array}{l}\text { RR 0,94 (IC de } 95 \% 0,49 \text { à } \\
1,80) \\
\text { Basé sur } 572 \text { cas d'influenza } \\
\text { dans } 4 \text { ERC }\end{array}$ & $104^{\star}$ & $\begin{array}{c}-6 \\
(-53 \text { à } 84)\end{array}$ & $\begin{array}{l}\text { Très faible } \oplus \Theta \Theta \Theta \\
\text { (Données très indirectes et } \\
\text { grande imprécision) } \dagger\end{array}$ & $\begin{array}{l}\text { Le plasma de convalescent pourrait } \\
\text { avoir peu ou pas d'effets sur la } \\
\text { mortalité, mais les données sont } \\
\text { très incertaines. }\end{array}$ \\
\hline Mortalité (jour 22) & $\begin{array}{l}\text { RR 0,10 (IC de } 95 \% 0,01 \text { à } \\
1,70 \text { ) } \\
\text { Basé sur } 40 \text { cas de SRAS dans } \\
\text { une étude d'observation }\end{array}$ & $104^{\star}$ & $\begin{array}{c}-94 \\
(-103 \text { à } 73)\end{array}$ & $\begin{array}{l}\text { Très faible } \oplus \Theta \Theta \Theta \\
\text { (Données très indirectes, très } \\
\text { grand risque de biais et } \\
\text { grande imprécision) } \ddagger\end{array}$ & $\begin{array}{l}\text { Le plasma de convalescent pourrait } \\
\text { avoir un effet important sur la } \\
\text { mortalité (augmentation ou } \\
\text { diminution), mais les données sont } \\
\text { très incertaines. }\end{array}$ \\
\hline $\begin{array}{l}\text { Rétablissement au jour } \\
28 \text {, mesuré à l'aide d'une } \\
\text { échelle ordinale de } 6 \\
\text { points§ }\end{array}$ & $\begin{array}{l}\text { RC proportionnel pour le } \\
\text { rétablissement } \$ \\
\mathrm{RC} 1,05 \text { (IC de } 95 \% 0,67 \text { à } \\
1,64) \\
\text { Basé sur } 438 \text { cas d'influenza } \\
\text { dans } 2 \text { ERC }\end{array}$ & $104^{\star}$ & $\begin{array}{c}5 \\
(-30 \text { à } 56)\end{array}$ & $\begin{array}{l}\text { Très faible } \oplus \Theta \Theta \Theta \\
\text { (Données très indirectes et } \\
\text { grande imprécision) } \dagger\end{array}$ & $\begin{array}{l}\text { Le plasma de convalescent pourrait } \\
\text { avoir peu ou pas d'effets sur le } \\
\text { rétablissement, mais les données } \\
\text { sont très incertaines. }\end{array}$ \\
\hline $\begin{array}{l}\text { Durée d'hospitalisation } \\
\text { (jours) }\end{array}$ & $\begin{array}{l}\text { Basé sur } 259 \text { cas d'influenza } \\
\text { dans } 3 \text { ERC }\end{array}$ & $\begin{array}{l}\text { Médiane: } \\
\qquad 139\end{array}$ & $\begin{array}{c}\text { DM }-1.62 \\
(-3.82 \text { à } 0.58)\end{array}$ & $\begin{array}{l}\text { Très faible } \oplus \Theta \Theta \Theta \\
\text { (Données très indirectes et } \\
\text { grande imprécision) } \dagger\end{array}$ & $\begin{array}{l}\text { Le plasma de convalescent pourrait } \\
\text { réduire légèrement la durée } \\
\text { d'hospitalisation, mais les données } \\
\text { sont très incertaines. }\end{array}$ \\
\hline $\begin{array}{l}\text { Durée d'hospitalisation } \\
\text { aux soins intensifs } \\
\text { (jours) }\end{array}$ & $\begin{array}{l}\text { Basé sur } 149 \text { cas d'influenza } \\
\text { dans } 2 \text { ERC }\end{array}$ & Médiane $: 7^{\star \star}$ & $\begin{array}{c}\text { DM }-0.32 \\
(-3.20 \text { à } 2.56)\end{array}$ & $\begin{array}{l}\text { Très faible } \oplus \Theta \Theta \Theta \\
\text { (Données très indirectes et } \\
\text { grande imprécision) } \dagger\end{array}$ & $\begin{array}{l}\text { Le plasma de convalescent pourrait } \\
\text { ne pas réduire ou pourrait réduire } \\
\text { peu la durée d'hospitalisation aux } \\
\text { soins intensifs, mais les données } \\
\text { sont très incertaines. }\end{array}$ \\
\hline $\begin{array}{l}\text { Durée de la ventilation } \\
\text { mécanique (jours) }\end{array}$ & $\begin{array}{l}\text { Basé sur } 83 \text { cas d'influenza } \\
\text { dans } 2 \text { ERC }\end{array}$ & $\begin{array}{l}\text { Médiane: } \\
9,25^{\star \star}\end{array}$ & $\begin{array}{c}\text { DM }-3.67 \\
(-7.70 \text { à } 0.36)\end{array}$ & $\begin{array}{l}\text { Très faible } \oplus \Theta \Theta \Theta \\
\text { (Données très indirectes et } \\
\text { grande imprécision) } \dagger\end{array}$ & $\begin{array}{l}\text { Le plasma de convalescent pourrait } \\
\text { réduire la durée de la ventilation } \\
\text { mécanique, mais les données sont } \\
\text { très incertaines. }\end{array}$ \\
\hline $\begin{array}{l}\text { Événements } \\
\text { indésirables graves }\end{array}$ & $\begin{array}{l}\text { RR : } 0,85 \text { (IC de } 95 \% \text { : } 0,56 \text { à } \\
1,29) \\
\text { Basé sur } 576 \text { cas d'influenza } \\
\text { dans } 3 \text { ERC }\end{array}$ & $80 \dagger \uparrow$ & $\begin{array}{c}-12 \\
(-35 \text { à } 23)\end{array}$ & $\begin{array}{l}\text { Faible } \oplus \oplus \Theta \Theta \\
\text { (Données très indirectes et } \\
\text { imprécision) }\end{array}$ & $\begin{array}{l}\text { Le plasma de convalescent pourrait } \\
\text { avoir peu ou pas d'effets sur le } \\
\text { nombre d'événements indésirables } \\
\text { graves. }\end{array}$ \\
\hline
\end{tabular}

Remarque : COVID-19 = maladie à coronavirus 2019; DM = différence moyenne; ERC = essai randomisé et contrôlé; GRADE = Grading of Recommendations Assessment, Development, and Evaluation; $I C=$ intervalle de confiance; $R C=$ rapport de cotes; $R R=$ risque relatif; $S R A S=$ syndrome respiratoire aigu sévère.

*Risque de référence des patients hospitalisés pour la COVID-19 n'ayant pas reçu de plasma de convalescent ni de stéroïdes, tiré de l'article de Guan et de ses collaborateurs ${ }^{3}$. Dans cet article, 96 patients gravement malades sur 173 n'ont pas reçu de stéroïdes ni de plasma hyperimmun, et 10 d'entre eux sont décédés. (Dr W. Guan, Principal laboratoire d’État sur les affections respiratoires, Centre national de recherche clinique sur les affections respiratoires, Institut de santé respiratoire de Guangzhou, Premier hôpital affilié au Centre hospitalier universitaire de Guangzhou, Guangzhou, province du Guangdong, Chine; communication personnelle, 2020). Ainsi, le risque de mortalité de référence est de 10/96 (10,4\%). La durée médiane d'hospitalisation était de 12,0 jours (moyenne 12,8 jours).

†Deux niveaux ont été retirés en raison des données indirectes puisque les caractéristiques cliniques et épidémiologiques des patients atteints de l'influenza diffèrent de celles des patients atteints de la COVID-19. Un niveau a été retiré en raison de l'imprécision parce que l'intervalle de confiance indiquait à la fois des bénéfices et des préjudices importants. łLes données des études d'observation étaient, au départ, des données de faible qualité. Un niveau a été retiré en raison des données indirectes, qui portaient sur le SRAS plutôt que sur la COVID-19. Un niveau a été retiré pour l'imprécision, l'intervalle de confiance indiquant à la fois des bénéfices et des préjudices importants.

§Rétablissement en tant que paramètre ordinal ( 6 catégories mutuellement exclusives) à 28 jours : décès, hospitalisation aux soins intensifs, hospitalisation avec oxygénothérapie, hospitalisation sans oxygénothérapie, congé et rétablissement incomplet, congé et rétablissement complet. Un RC supérieur à 1 indique que l'intervention étudiée est meilleure que le traitement de comparaison, ce qui signifie que la probabilité de rétablissement est 1,24 fois plus élevée dans le groupe plasma hyperimmun que dans le groupe témoin. Ce RC est semblable d'une catégorie à l'autre. Nous avons supposé que la différence de risques entre les groupes de traitement reste la même pour les diverses catégories. ฯDurée médiane d'hospitalisation des patients atteints de la forme grave de la COVID-19, tirée de l'article de Guan et de ses collaborateurs ${ }^{3}$.

${ }^{\star *}$ Nombre médian de jours aux soins intensifs, calculé en se basant sur les groupes témoins des ERC comportant des patients atteints de la forme grave de l'influenza. ††Risque de référence pour les événements indésirables graves, calculé en se basant sur les groupes témoins des études sur l'influenza (3 études).

¥¥Un niveau a été retiré en raison du caractère indirect des données relatives à l'innocuité, qui laissait croire que les événements indésirables étaient probablement semblables d'une infection virale à l'autre; un niveau a également été retiré pour l'imprécision, l'intervalle de confiance indiquant à la fois des bénéfices et des préjudices importants.

essais ont donné des résultats négatifs parce que du véritable plasma de convalescent n'a pas été utilisé ${ }^{40}$. Ce raisonnement supposerait donc que les essais sur l'efficacité du plasma de convalescent en cas de COVID-19 devraient comprendre le pré- lèvement de plasma chez des personnes récemment rétablies et devraient fournir le nombre de jours écoulés depuis le rétablissement, de même que les résultats du plasma aux tests sérologiques et fonctionnels. Les essais ainsi conçus 


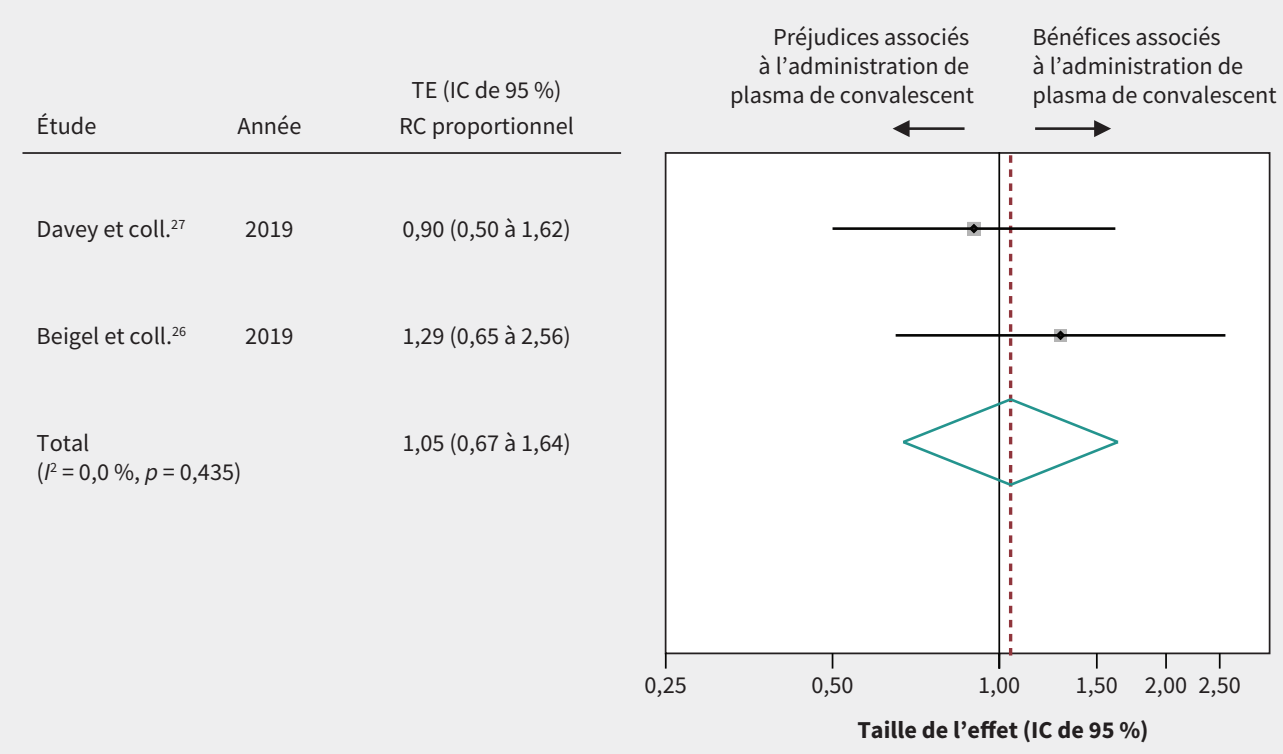

Figure 4 : Efficacité du plasma de convalescent sur le rétablissement d'une infection respiratoire aiguë virale. La pondération provient des analyses à effets aléatoires. Remarque $: \mathrm{IC}=$ intervalle de confiance, $\mathrm{RC}=$ rapport de cotes, $\mathrm{TE}=$ taille de l'effet.

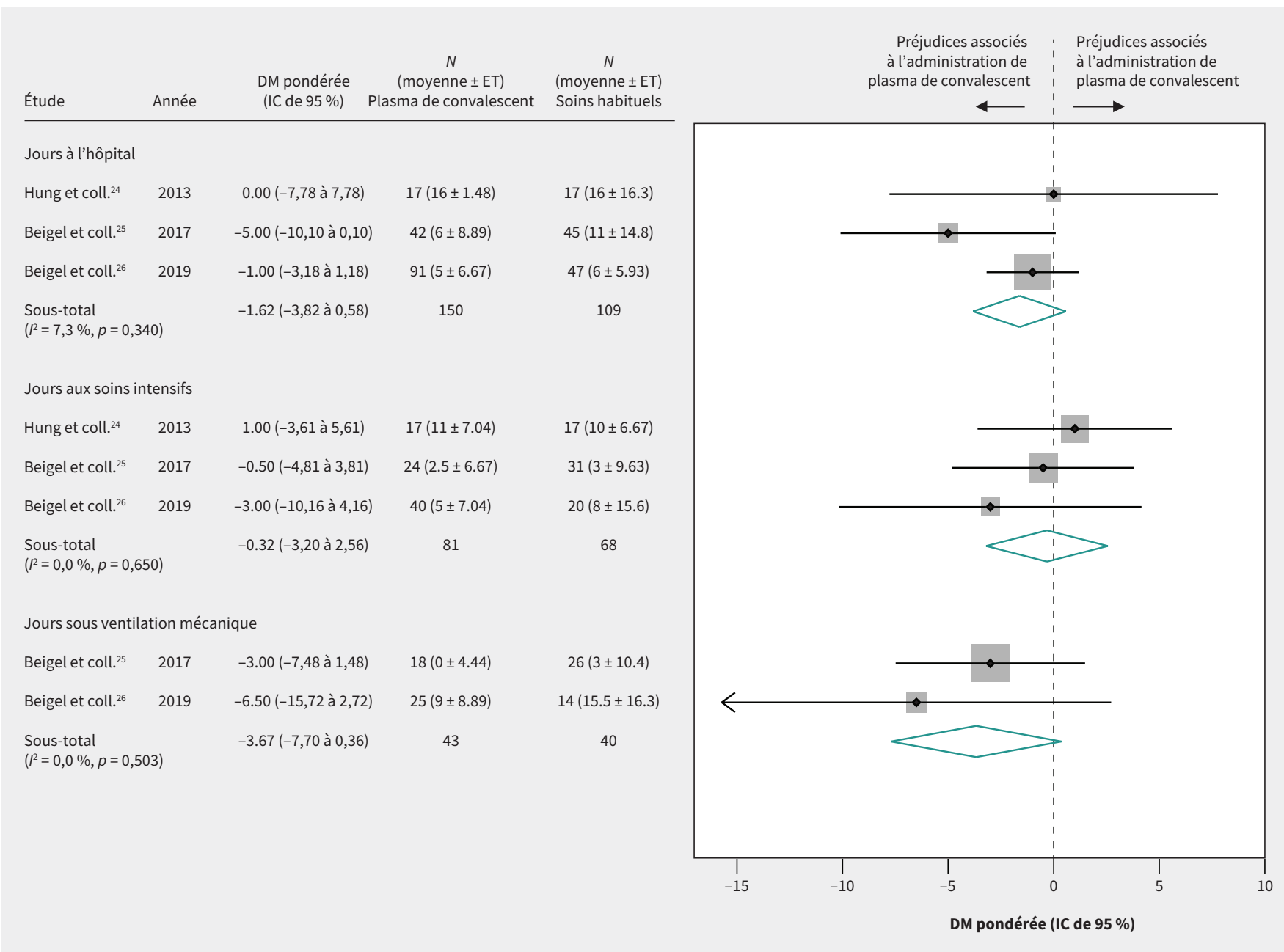

Figure 5 : Efficacité du plasma de convalescent sur la réduction de la durée d'hospitalisation. La pondération provient des analyses à effets aléatoires. Remarque : DM = différence moyenne, $\mathrm{ET}=$ écart-type, IC = intervalle de confiance. 


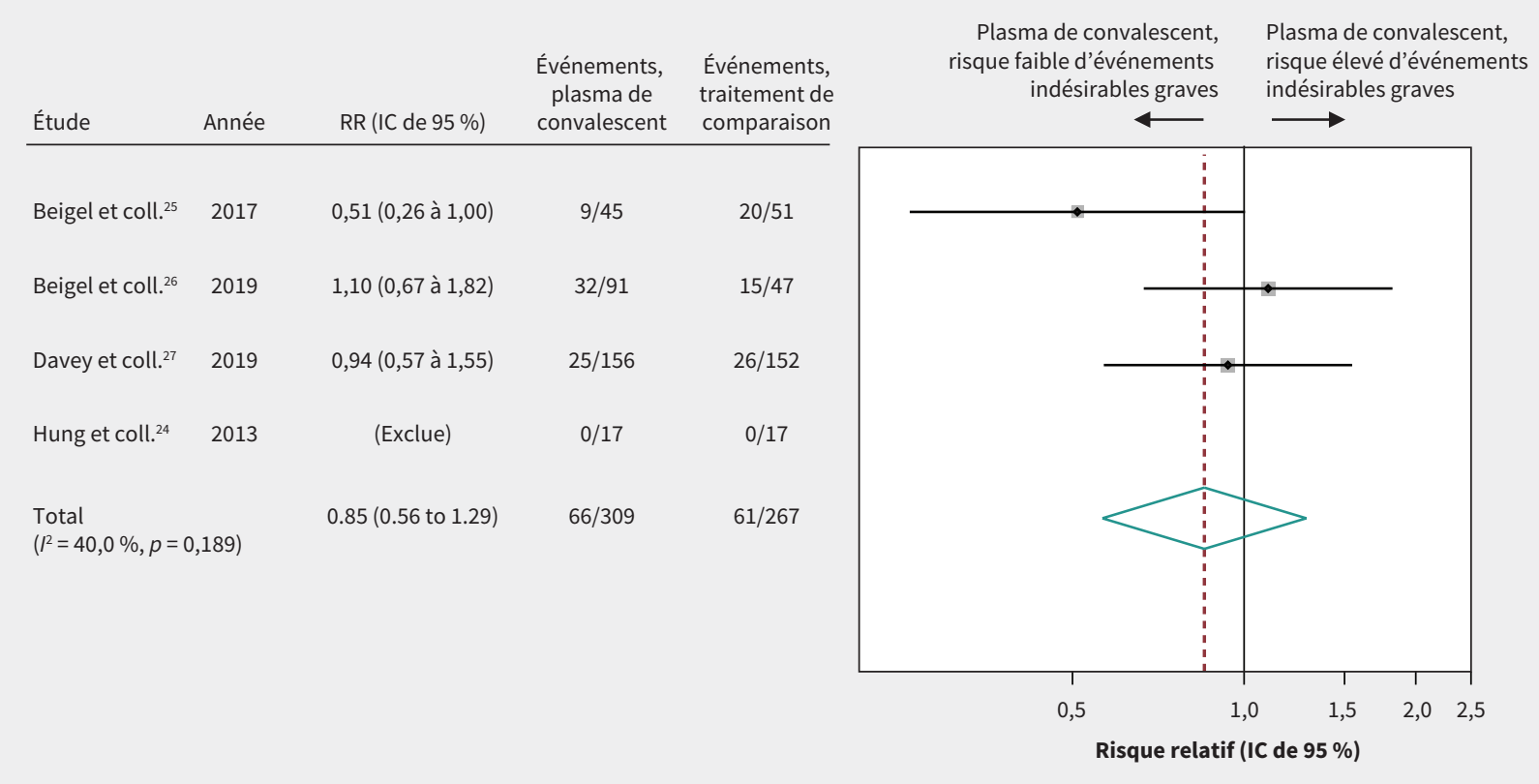

Figure 6: Innocuité du plasma de convalescent. La pondération provient des analyses à effets aléatoires. Remarque : IC= intervalle de confiance, RR= risque relatif.

réduiraient considérablement les doutes et les raisons données pour expliquer l'absence de bénéfices dans les études.

\section{Conclusion}

L'intérêt du plasma de convalescent réside dans son faible taux apparent d'événements indésirables graves. Cependant, cet avantage, par rapport à d'autres traitements non éprouvés contre la COVID-19, ne suffit pas pour justifier l'utilisation du plasma de convalescent en l'absence de données en montrant son efficacité. Le prélèvement de plasma de convalescent mobilise des ressources qui, en l'absence de preuves fiables de son efficacité, pourraient être plus utiles ailleurs. L'utilisation répandue du plasma de convalescent devrait donc être conditionnelle à l'obtention de données de grande qualité dans le cadre d'essais randomisés portant idéalement sur les effets du plasma de personnes récemment rétablies de la COVID-19. La priorisation des essais cliniques sur l'efficacité du plasma de convalescent plutôt que d'autres options thérapeutiques non éprouvées pour la COVID-19 devrait reposer sur les données disponibles, mais aussi sur le contexte sociopolitique. Il est urgent de déterminer la valeur du plasma de convalescent, des cliniciens ayant déjà commencé à traiter des patients atteints de la COVID-19 en milieu hospitalier, hors du cadre d'essais cliniques.

\section{Références}

1. Coronavirus disease (COVID-2019) situation reports. Geneva: World Health Organization; 2020. Accessible ici : www.who.int/emergencies/diseases/novelcoronavirus-2019/situation-reports (consulté le 27 avril 2020).

2. Wu Z, McGoogan JM. Characteristics of and important lessons from the coronavirus disease 2019 (COVID-19) outbreak in China: summary of a report of 72314 cases from the Chinese Center for Disease Control and Prevention. JAMA 24 février 2020 [Cyberpublication avant impression]. doi: 10.1001/jama.2020.2648.

3. Guan WJ, Ni ZY, Hu Y, et al., China Medical Treatment Expert Group for COVID19. Clinical characteristics of coronavirus disease 2019 in China. N Engl J Med 2020;382:1708-20.
4. Zhou F, Yu T, Du R, et al. Clinical course and risk factors for mortality of adult inpatients with COVID-19 in Wuhan, China: a retrospective cohort study. Lancet 2020;395:1054-62.

5. Wang $\mathrm{Y}$, Wang $\mathrm{Y}, \mathrm{Chen} \mathrm{Y}$, et al. Unique epidemiological and clinical features of the emerging 2019 novel coronavirus pneumonia (COVID-19) implicate special control measures. J Med Virol 5 mars 2020 [Cyberpublication avant impression]. doi: 10.1002/jmv.25748.

6. Mair-Jenkins J, Saavedra-Campos M, Baillie JK, et al.; Convalescent Plasma Study Group. The effectiveness of convalescent plasma and hyperimmune immunoglobulin for the treatment of severe acute respiratory infections of viral etiology: a systematic review and exploratory meta-analysis. J Infect Dis 2015;211:80-90.

7. Zhang L, Liu Y. Potential interventions for novel coronavirus in China: a systematic review. J Med Virol 2020;92:479-90.

8. Lee JS, Adhikari NKJ, Kwon HY, et al. Anti-Ebola therapy for patients with Ebola virus disease: a systematic review. BMC Infect Dis 2019;19:376.

9. Stockman LJ, Bellamy R, Garner P. SARS: systematic review of treatment effects. PLoS Med 2006;3:e343.

10. Luke TC, Kilbane EM, Jackson JL, et al. Meta-analysis: convalescent blood products for Spanish influenza pneumonia: A future H5N1 treatment? Ann Intern Med 2006;145:599-609.

11. Use of convalescent whole blood or plasma collected from patients recovered from Ebola virus disease for transfusion, as an empirical treatment during outbreaks. Geneva: World Health Organization; 2014. Accessible ici : www.who.int/csr/resources/ publications/ebola/convalescent-treatment/en (consulté le 25 mars 2020).

12. Cheng Y, Wong R, Soo YO, et al. Use of convalescent plasma therapy in SARS patients in Hong Kong. Eur J Clin Microbiol Infect Dis 2005;24:44-6.

13. Schoofs T, Klein F, Braunschweig M, et al. HIV-1 therapy with monoclonal antibody 3BNC117 elicits host immune responses against HIV-1. Science 2016; 352:997-1001.

14. Ye Z, Rochwerg B, Wang Y, et al. Treatment of patients with nonsevere and severe coronavirus disease 2019: an evidence-based guideline. CMAJ 4 mai 2020 [Cyberpublication avant impression]. doi: 10.1503/cmaj.200648.

15. Moher D, Liberati A, Tetzlaff J, et al.; PRISMA Group. Preferred reporting items for systematic reviews and meta-analyses: the PRISMA statement. $J$ Clin Epidemiol 2009;62:1006-12.

16. Clinical management of severe acute respiratory infection when COVID-19 is suspected [Interim guidance]. Geneva: World Health Organization; 2020. Accessible ici : www.who.int/publications-detail/clinical-management-of -severe-acute-respiratory-infection-when-novel-coronavirus-(ncov)-infection -is-suspected (consulté le 21 mars 2020).

17. Guyatt G, Busse JW. Risk of bias in randomized trials. GROWTH Evidence; 2016. Accessible ici : https://growthevidence.com/gordon-h-guyatt-md-msc-and -jason-w-busse-dc-phd (consulté le 24 mars 2020). 
18. Guyatt GH, Busse J. Methods commentary: risk of bias in cohort studies. Ottawa: Evidence Partners. Accessible ici : www.evidencepartners.com/ resources/methodological-resources/risk-of-bias-in-cohort-studies (consulté le 24 mars 2020).

19. Guyatt G, Oxman AD, Akl EA, et al. GRADE guidelines: 1. Introduction-GRADE evidence profiles and summary of findings tables. J Clin Epidemiol 2011;64: 383-94.

20. Guyatt GH, Oxman AD, Santesso N, et al. GRADE guidelines: 12. Preparing summary of findings tables - binary outcomes. J Clin Epidemiol 2013;66:158-72.

21. Guyatt GH, Thorlund K, Oxman AD, et al. GRADE guidelines: 13. Preparing summary of findings tables and evidence profiles - continuous outcomes. J Clin Epidemiol 2013;66:173-83.

22. Higgins JPT, Green S, editors. 7.7.3.5. Medians and interquartile ranges. In: Cochrane Handbook for Systematic Reviews of Interventions. Version 5.1.0. Oxford (UK): Cochrane Collaboration; 2011. Accessible ici : https://handbook-5-1.cochrane.org/chapter_7/7_7_3_5_mediansand_interquartile_ranges .htm (consulté le 20 mars 2020).

23. Soo YO, Cheng Y, Wong R, et al. Retrospective comparison of convalescent plasma with continuing high-dose methylprednisolone treatment in SARS patients. Clin Microbiol Infect 2004;10:676-8.

24. Hung IFN, To KKW, Lee CK, et al. Hyperimmune IV immunoglobulin treatment: a multicenter double-blind randomized controlled trial for patients with severe 2009 influenza A(H1N1) infection. Chest 2013;144:464-73.

25. Beigel JH, Tebas P, Elie-Turenne MC, et al.; IRC002 Study Team. Immune plasma for the treatment of severe influenza: an open-label, multicentre, phase 2 randomised study. Lancet Respir Med 2017;5:500-11.

26. Beigel JH, Aga E, Elie-Turenne MC, et al.; IRC002 Study Team. Anti-influenza immune plasma for the treatment of patients with severe influenza A: a randomised, double-blind, phase 3 trial. Lancet Respir Med 2019;7:941-50.

27. Davey RT Jr, Fernández-Cruz E, Markowitz N, et al.; INSIGHT FLU-IVIG Study Group. Anti-influenza hyperimmune intravenous immunoglobulin for adults with influenza A or B infection (FLU-IVIG): a double-blind, randomised, placebo-controlled trial. Lancet Respir Med 2019;7:951-63.

28. van Griensven J, Edwards T, de Lamballerie X, et al. Ebola-Tx Consortium. Evaluation of convalescent plasma for Ebola virus disease in Guinea. N Engl J Med 2016; 374:33-42.
29. Recommendations for investigational COVID-19 convalescent plasma. Silve Sprint (MD): US Food and Drug Administration; 2020. Accessible ici : www. fda.gov/vaccines-blood-biologics/investigational-new-drug-ind-or-device -exemption-ide-process-cber/investigational-covid-19-convalescent-plasma -emergency-inds (consulté le 26 mars 2020).

30. Kalil AC. Treating COVID-19-off-label drug use, compassionate use, and randomized clinical trials during pandemics. JAMA 24 mars 2020 [Cyberpublication avant impression]. doi: 10.1001/jama.2020.4742.

31. Zhou XZ, et al. Epidemiologic features, clinical diagnosis and therapy of first cluster of patients with severe acute respiratory syndrome in Beijing area [article en chinois]. Zhonghua Yi Xue Za Zhi 2003;83:1018-22.

32. Xu Z, Zhou J, Huang Y, et al. The efficacy of convalescent plasma for the treat ment of severe influenza. medRxiv 25 février 2020. doi: 10.1101/2020.02.20. 20025593.

33. COVID-19 SARS-CoV-2 preprints from medRxiv and bioRxiv. medRxiv; 2020 Accessible ici : https://connect.medrxiv.org/relate/content/181 (consulté le 11 mars 2020).

34. INSIGHT FLU005 IVIG Pilot Study Group. INSIGHT FLU005: an anti-influenza virus hyperimmune intravenous immunoglobulin pilot study. J Infect Dis 2016; 213:574-8.

35. Shen C, Wang Z, Zhao F, et al. Treatment of 5 critically ill patients with COVID 19 with convalescent plasma. JAMA 27 mars 2020 [Cyberpublication avant impression]. doi: 10.1001/jama.2020.4783.

36. Duan K, Liu B, Li C, et al. Effectiveness of convalescent plasma therapy in severe COVID-19 patients. Proc Natl Acad Sci U S A 2020;117:9490-6.

37. Zhang B, Liu S, Tan T, et al. Treatment with convalescent plasma for critically ill patients with SARSCoV-2 infection. Chest 31 mars 2020 [Cyberpublication avant impression]. pii: S0012-3692(20)30571-7. doi: 10.1016/j.chest.2020.03.039.

38. Mulangu S, Dodd LE, Davey RT Jr, et al.; PALM Consortium Study Team. A randomized, controlled trial of Ebola virus disease therapeutics. N Engl J Med 2019;381:2293-303.

39. Shi Y, Wang Y, Shao C, et al. COVID-19 infection: the perspectives on immune responses. Cell Death Differ 2020;27:1451-4.

40. Kanjilal S, Mina MJ. Passive immunity for the treatment of influenza: quality not quantity. Lancet Respir Med 2019;7:922-3.
Intérêts concurrents : Mark Loeb a reçu des honoraires personnels et un soutien non financier de Sanofi, un soutien non financier de l'Organisation mondiale de la Santé, une subvention et des honoraires personnels de Seqirus, ainsi que des honoraires personnels de Pfizer, de Medicago et des National Institutes of Health. Philippe Bégin est cochercheur principal pour un essai clinique randomisé multicentrique sur l'utilisation du plasma en cas de maladie à coronavirus 2019 (COVID-19). Il a reçu des honoraires personnels de Novartis, de Pfizer, de Sanofi, d'ALK et d'Aralez, de même que des subventions de DBV Technologies, de Regeneron et de Sanofi pour des travaux autres que la présente étude. Aucun autre intérêt concurrent n'a été déclaré

Cet article a été révisé par des pairs.

Affiliations : Instituts indiens de santé publique de Delhi (N. Devasenapathy), Fondation de santé publique de l'Inde, Gurgaon, Haryana, Inde; Département des méthodes, des données et de l'incidence de la recherche en santé (Z. Ye, M. Loeb, F. Fang, B. Tadayon Najafabadi, Y. Xiao, R. Couban, G. Guyatt), Université McMaster, Hamilton, Ont.; Université de médecine chinoise de Guangzhou (F. Fang),
Guangzhou, Guangdong, Chine; École de soins infirmiers de Chine occidentale et Hôpital de Chine occidentale (Y. Xiao), Université du Sichuan, Chengdu, Sichuan, Chine; Département de médecine (p. Bégin), Université de Montréal, Montréal, Qué.

Collaborateurs : Niveditha Devasenapathy était en charge de la revue systématique; elle a réalisé la méta-analyse, interprété les résultats, rédigé la première version du manuscrit et pris la décision finale quant à la soumission de l'article en vue de sa publication. Gordon Guyatt a approuvé la méthodologie de la revue, interprété les résultats, fourni des commentaires constructifs sur le manuscrit et approuvé la version définitive. Fang et Yingqi Xiao ont réalisé la recherche dans les bases de données chinoises. Borna Tadayon Najafabadi a pris part à l'examen des études admissibles et à l'extraction des données. Zhikang Ye a participé à la conception de la revue systématique et à l'interprétation des résultats. Fang, Yingqi Xiao et Borna Tadayon Najafabadi ont contribué à l'examen et à l'extraction des données. Mark Loeb et Philippe Bégin ont collaboré à l'interprétation des résultats de l'étude et ont fourni des commentaires con- structifs sur le manuscrit. Rachel Couban, spécialiste en information médicale, a établi et dirigé la stratégie de recherche. Tous les auteurs ont révisé de façon critique le contenu intellectuel important du manuscrit. Niveditha Devasenapathy, Gordon Guyatt et Zhikang Ye avaient accès sans restriction à toutes les données de l'étude. Tous les auteurs ont donné leur approbation finale pour la version soumise pour publication et assument l'entière responsabilité de tous les aspects du travail.

Partage des données : Les données extraites des études incluses sont présentées dans les résultats; toutefois, les tableaux complets de ces données peuvent être obtenus de l'auteure-ressource si la demande est jugée raisonnable.

Remerciements : Les auteurs remercient Quazi Ibrahim pour ses conseils statistiques. Yingqi Xiao a reçu une bourse du China Scholarship Council (no 201906240082).

Accepté : $1^{\text {er }}$ mai 2020

Correspondance : Niveditha Devasenapathy, niveditha@iiphd.org 